\title{
A novel injection for chronic urticaria by autologous serum derived whole blood
}

\section{Mahdieh Ghiasi $^{1 *}$, Mohamad Mehdizadeh², Amir Ali Hamidieh ${ }^{3}$}

${ }^{1}$ Iranian Tissue Bank \& Research Center, Gene, Cell \& Tissue Research Institute, Tehran University of Medical Sciences, Tehran, Iran.

${ }^{2}$ Dental and Oral Research Center, Department of Oral and Maxillofacial Surgery, School of Dentistry, Qom University of Medical Sciences, Qom, Iran.

${ }^{3}$ Iranian Tissue Bank \& Research Center, Gene, Cell \& Tissue Research Institute, Tehran University of Medical Sciences, Tehran, Iran.

*Corresponding Author: Mahdieh Ghiasi, Iranian Tissue Bank \& Research Center, Gene, Cell \& Tissue Research Institute, Tehran University of Medical Sciences, Tehran, Iran.

Received date: 14 October 2021; Accepted date: 05 November 2021; Published date: 08 November 2021

Citation: Ghiasi M, Mehdizadeh M, Hamidieh AA (2021) A novel injection for chronic urticaria by autologous serum derived whole blood. J Comm Med and Pub Health Rep 2(11): https://doi.org/10.38207/JCMPHR/2021/0211208

Copyright: (C) 2021 Mahdieh Ghiasi. This is an open-access article distributed under the terms of the Creative Commons Attribution License, which permits unrestricted use, distribution, and reproduction in any medium, provided the original author and source are credited.

\begin{abstract}
Background: Chronic urticaria $(\mathrm{CU})$ is the most challenging in medicine and patients suffer from irritable itch and weal's and need to use a huge antihistamine pill burden. Therefore, there is a need for more effective modalities to reduce pill burden. evaluation of the effectiveness of autologous serum therapy (AST) performs for CU patients.

Materials and Methods: Two patients were selected for this treatment. whole blood samples were obtained from the patients by 5 ml syringes and processed to prepare serum for injection. It was repeated 8 times every 7 days. They were evaluated for 24 weeks after the last injection by a dermatologist.
\end{abstract}

Results: our results by Follow-up visits during treatment showed that AST can be used as a new modality in Chronic urticaria (CU) patients with high efficiency and no recurrence of the disease.

Conclusion: a promising treatment for CU is AST without side effects and limitations.

Keywords: autologous serum therapy, Chronic urticaria, whole blood

\section{Introduction}

Chronic urticaria $(\mathrm{CU})$ is the most common skin disease that occurs with extensive itchy wheals angioedema or both for the duration of 6 or more weeks. [1] There is a main challenge for this disease in the light of etiology, investigations, and management. [2] Chronic urticaria disease occurs unpredictably with an exceedingly difficult period as they suffer from irritable itch and weals and tolerance to high use of antihistamines pill. Some studies have evaluated the effectiveness of various second-generation antihistamines as the firstline treatment for chronic urticaria. [3-6] Due to the limited effectiveness of antihistamines, new treatments are needed for extending relief and reducing pill burden. Autoreactive mechanisms occurred in $30-50 \%$ of all CU patients. Injection of their serum is caused an immediate hypersensitivity-type skin reaction in them. At this event, the expression of autoantibodies directed against the high-

\section{Study design:}

Tow patients were selected for AST according to a dermatologist Screening visit. They have autologous serum skin test (ASST) (+) with CU. This study has been approved by the ethics committee. The treatment process is as follows:1. Patient profile: age: 21 and 48 years; duration of the disease: 5 months to 1 year. (Respectively)2. It affinity receptor for $\operatorname{IgE}\left(\operatorname{anti}-\mathrm{Fc}_{\varepsilon} \mathrm{RI}\right)$ of mast cells or $\operatorname{IgE}(\operatorname{anti}-\mathrm{IgE}$ ) acts as the main factor. Autohemotherapy has been known as a different type of treatment for autoreactive CU patients Of course with repeated injections of autologous serum. However, in Indian medicine, this treatment has been used for many years in an extensive range of diseases such as osteoarthritis, atopic dermatitis, chronic inflammation, allergies, immunodeficiency, vascular diseases, and various other skin disorders. $[7,8]$

Auto-chemotherapy is able that relieve or stimulate the sensitivity of arCU patients to the proinflammatory signals expressed in their circulation. Auto-chemotherapy can consider as an effective technique in autologous serum skin test (ASST)-positive CU. [9] This study aimed to evaluate the response of AST for CU patients to control the use of antihistamines and reduce patient costs.

is done in 8 repetitions every 7 days.3. In each session of treatment, 5 $\mathrm{ml}$ of blood is collected in Vacutainer plastic tubes and centrifuged at 3500 r.p.m. for $10 \mathrm{~min}$. The sera are then separated with $5 \mathrm{~cm} 3$ syringes. $2.5 \mathrm{ml}$ of the serum is injected intramuscularly into the gluteus muscle in each session of treatment. 
Results: During the 24 weeks of patient follow-up, they had excellent improvement and significant changes in the symptoms of the disease. Their improvement was confirmed by a dermatologist during follow-up. (Figure 1)

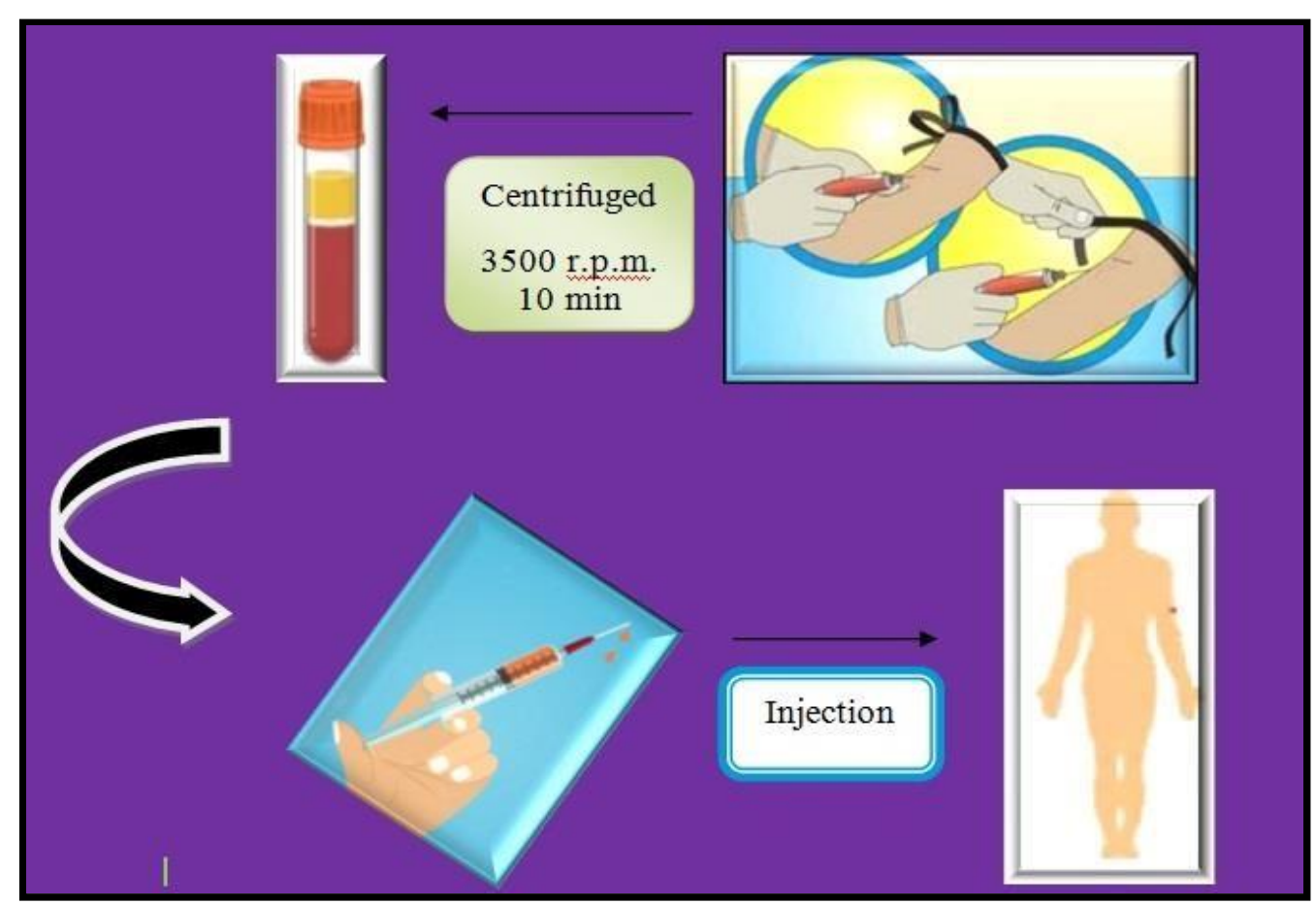

Figure 1: the process of autologous serum isolation from patients.

\section{Discussion}

From, the time of Heberden until now, urticaria has been affected patients' quality of life in the aspect of emotion, functioning, and symptoms. [10,11]

one of the problems for physicians is $\mathrm{CU}$ treatment. Antihistamines are the most prescribed treatment, and of course, in some patients, there is drug resistance, and the dermatologist is forced to use systemic steroids or other immunosuppressive drugs on a regular. The use of these drugs causes patients to complain.

Our findings show that AST is a new method in ASST-positive CSU patients with useful clinical effects due to autoantibodies changes. it

\section{Conclusion}

A new method in chronic urticaria is AST which can reduce the pill burden and improve the quality of life. Weekly injections can do easily done in a short time and cause patient satisfaction

\section{References}

1. Zuberbier T, Aberer W, Asero R, Latiff AHA, Baker D, et al. (2018) EAACI/GA2LEN/EDF/WAO guideline: management of urticaria. Allergy. 64: 1427-1443.

2. O'Donnell BF, Lawlor F, Simpson J, Morgan M, Greaves MW (1997) The impact of chronic urticaria on the quality of life. Br J Dermatol. 136(2): 197-201.

3. Sil A, Tripathi SK, Chaudhuri A, Das NK, Hazra A, et al. (2013) Olopatadine versus levocetirizine in chronic urticaria: An observer-blind, randomized, controlled trial of effectiveness and safety. J Dermatolog Treat. 24(6): 466-72.

4. Okubo Y, Shigoka Y, Yamazaki M, Tsuboi R (2013) Double dose of cetirizine hydrochloride is effective for patients with urticaria resistant: A prospective, randomized, non-blinded, comparative determined that the therapeutic efficacy of autologous serum injection is suitable in CU patients without special side effects.

In one study, Staubach et al. reported more effective autohemotherapy on their ASST-positive patients more than the ASST-negative ones. [12]

Bajaj et al. have been reported that more than $85 \%$ of patients responded well to autologous serum, which is consistent with the results of our study. [13]

Another study in India showed the effectiveness of AST by reducing the pill burden improving the quality of life. [14]

Acknowledgment: This work was supported by the corresponding author

Conflict of Interest: The authors declare that they have no conflict of interest.

clinical study and assessment of quality of life. J Dermatolog Treat. 24(2): 153-60.

5. Anuradha P, Maiti R, Jyothirmai J, Mujeebuddin O, Anuradha M (2010) Loratidine versus levocetirizine in chronic idiopathic urticaria: A comparative study of effcacy and safety. Indian J Pharmacol. 42(1): 12-6.

6. Zuberbier T, Asero R, Bindslev-Jensen C, Canonica G, Church MK, et al. (2009) EAACI/GA2LEN/EDF/WAO guideline: Management of urticaria. Allergy. 64(10): 1427-43.

7. Pittler MH, Armstrong NC, Cox A, Collier PM, Hart A, et al. (2003) Randomized, double-blind, placebo-controlled trial of autologous blood therapy for atopic dermatitis. $\mathrm{Br} \mathrm{J}$ Dermatol. 148(2): 307-13. 
8. Behl PN. Practice of Dermatology. 7th ed. New Delhi: Oxford Blackwell Scientific publications; 1990. Autohaemotherapy; p. 76 .

9. Staubach P, Onnen K, Vonend A, Metz M, Siebenhaar F, et al. (2006) Autologous whole blood injections to patients with chronic urticaria and a positive autologous serum skin test: A placebo-controlled trial. Dermatology. 212(2): 150-9.

10. Maurer M, Ortonne JP, Zuberbier T (2009) Chronic urticaria: A patient survey on quality-of-life, treatment usage and doctorpatient relation. Allergy. 64(4): 581-8.

11. Grob JJ, Gaudy-Marqueste C (2006) Urticaria and quality of life. Clin Rev Allergy Immunol. 30(1): 47-51.
Staubach P, Onnen K, Vonend A, Metz M, Siebenhaar F, et al.

(2006) Autologous whole blood injections to patients with chronic urticaria and a positive autologous serum skin test: A placebo-controlled trial. Dermatology. 212(2): 150-9.

13. Bajaj AK, Saraswat A, Upadhyay A, Damisetty R, Dhar S (2008) Autologous serum therapy in chronic urticaria: Old wine in a new bottle. Indian J Dermatol Venereol Leprol. 74(2): 109-13.

14. Sil A, Datta PK, Bandyopadhyay D, Das NK (2014) Autologous Serum Therapy in Chronic Urticaria: A Promising Complement to Antihistamines. Indian Journal of Dermatology. 59(4): 375-82.

12. 